\title{
A Simplified Mathematical Model for Fire Spread Predictions in Wildland Fires Combining between the Models of Anderson and Rothermel
}

\author{
Ali Karouni, Bassam Daya, Samia Bahlak, and Pierre Chauvet
}

\begin{abstract}
Predicting the potential behavior a forest fire is an essential task in fire management which aims to minimize the negative impact of fire on property and society. Many fire spread models were developed. They are either physics-based or empirical models. These mathematical models usually use a set of non-linear equations which are mostly complex and couldn't easily applied in developing countries like Lebanon. This paper poses a semi-empirical mathematical model referring to the experimental results used in Anderson's model (1983) and relying on Rothermel's model (1972). The proposed equation uses parameters of both weather and topography, where wind speed and direction, fuel moisture content and slope coefficient are introduced to obtain the expected spread rate (mile/hour).This proposed model is characterized by its simplicity and thus the possibility of implementation in Lebanon.
\end{abstract}

Index Terms-Fire spread rate, fuel moisture content, angle and slope coefficients.

\section{INTRODUCTION}

In general, "modelling wildland fire behavior seeks to address the prediction of the quantitative parameters which may be used to describe the spread of fire through a fuel bed"; Perry 1998 [1]. Models are divided into theoretical, empirical and semi-empirical. In theoretical models, the fire behavior is described using physical and chemical laws that govern combustion, fluid mechanics, and heat transfer. This in turn requires the use of large numbers of parameters in the equations for calculation. The obtained equations are often very complicated which makes its application even harder in real situations with real data especially in developing countries. Moreover, Validation of such models is extremely difficult due to the scalability and variability the phenomenon of wildland fires.

The first attempt in fire behavior modelling was by Fons (1946) in the United States [2]. It was a simplified theoretical example applying the energy conservation equation to a uniform volume of solid particles immersed in an ideal fire line in which fire spread and growth of fuel bed temperature could be obtained. Physical models are based on the analysis of the underlying physical and chemical processes. Albini [3],

Manuscript received February 27, 2014; revised April 28, 2014.

Ali Karouni and Samia Bahlak are with the Lebanese University, University Institute of Technology, Saida-Lebanon (e-mail: ali.karouni@etud.univ-angers.fr, samiabahlak@hotmail.com).

Bassam Daya is with Umm Al-Qura University, Faculty of Social Sciences, Information Science Department, Makkah - KSA (e-mail: b_daya@ul.edu.lb).

Pierre Chauvet is with Laris EA, L'Unam Université, Université d'Angers, Angers - France (e-mail: pierre.chauvet@uco.fr)
Grishin [4] and Weber [5] provided significant models of this sort. In the last decades, Butler et al., 2004 [6] and Alexander et al., [7] presented physical crown fire models.

Empirical models: These models constitute of statistical correlations coming from observations and experiments or studies on precedent wild land fires. These are limited to be applied to systems in which conditions are similar to those incidents tested. A good example is the McArthur model which predicts the rate of spread of Australian grassland fuel relying on temperature and humidity [8]. Stocks et al., 2004 presented one of the most prominent crowd fire models in the last decades [9].

Semi-empirical models: These models merge between simple physical algorithms, and completed through experimentation. Also in such models, the induction is reasonable in situations identical to those used in experiments. Semi-empirical models include often simplified equations with less number of parameters used, and popularly utilized by countries and organizations. Semi-empirical models have usually a rationale based on physical laws but the solution of the equations is accomplished by statistical analysis. This is the case with the most widely known and used Rothermel model [10], which forms the basis for computer applications such as FARSITE [11], Behave (Andrews [12], Burgan and Rothermel [13]), Sparks (SchÖning [14]).

Rothermel's model continues to be used to be used today as it has proven it's rigor in both the field and in theory. Many models that employ remote sensing as well as such techniques as finite difference, finite element, neural networks, and cellular automata use the Rothermel Model as a basic function. Despite its high importance, this model uses 24 parameters which makes its application very expensive and even impossible in developing countries like Lebanon.

In this paper, a simplified model equation is posed that merges between Fons experiments used by Anderson [15] and Rothermel [10]. The significance of the proposed model is in the minimized number of parameters used and the ease of extraction. Our model uses only five parameters: FMCwhich can be predicted from the fuel load of the witnessed area, wind speed $(\mathrm{mi} / \mathrm{h})$, wind direction, packing ratio, and the slope of the fuel bed. It is characterized by the type of parameters introduced, as both meteorological and topographic aspects are taken into account to obtain the spread rate (feet/min) in all directions reference to the direction of wind.

\section{THE SIMPLIFIED MODEL}

Due to the complexity of the utilized equations related to the rate of spread of forest fire regarding the numerous number of parameters used, which definitely do not suit 
developing countries due to the lack of the appropriate measuring tools and advanced laboratories, centres and even researchers, a simplified equation is generated using statistical results of Fons experiment, Table I, representing the rate of fire spread FSR based on the moisture content FMC and the wind speed and using Table III showing the fire spread rate in function of $\alpha$, the angle that is formed by the wind direction.

TABLE I: RATE OF FIRE SPREAD IN FUNCTION OF FMC AND WIND SPEED

\begin{tabular}{|c|c|c|c|c|}
\hline $\begin{array}{l}\text { Wind Speed } \\
(\mathrm{mi} / \mathrm{h})\end{array}$ & $\begin{array}{l}F S R \\
(\text { feet/min }) \\
F m c=4\end{array}$ & $\begin{array}{l}F S R \\
(\text { feet/min }) \\
F m c=8\end{array}$ & $\begin{array}{l}F S R \\
(\text { feet/min) } \\
F m c=12\end{array}$ & $\begin{array}{l}F S R \\
(\text { feet } / \mathrm{min}) \\
\text { Fmc }=16\end{array}$ \\
\hline 0 & 0,76 & 0,55 & 0,36 & 0,18 \\
\hline 2 & 1,78 & 1,28 & 0,89 & 0,51 \\
\hline 4 & 3,34 & 2,42 & 1,7 & 1,03 \\
\hline 6 & 5,38 & 4,01 & 2,85 & 1,78 \\
\hline 8 & 8,1 & 6,15 & 4,37 & 2,83 \\
\hline 10 & 11,75 & 8,97 & 6,46 & 4,24 \\
\hline 12 & 16,7 & 12,52 & 9,15 & 6,36 \\
\hline
\end{tabular}

TABLE II: THE COEFFICIENTS OF THE POLYNOMIAL EQUATIONS IN

\begin{tabular}{c|ccc}
\multicolumn{4}{|c}{ FUNCTION OF FMC } \\
\hline$F M C$ & $a$ & $b$ & $c$ \\
\hline 4 & 0,0936 & 0,1714 & 0,9326 \\
8 & 0,0702 & 0,1396 & 0,6383 \\
12 & 0,0534 & 0,0768 & 0,4457 \\
16 & 0,0417 & $-0,0036$ & 0,2733 \\
\hline
\end{tabular}

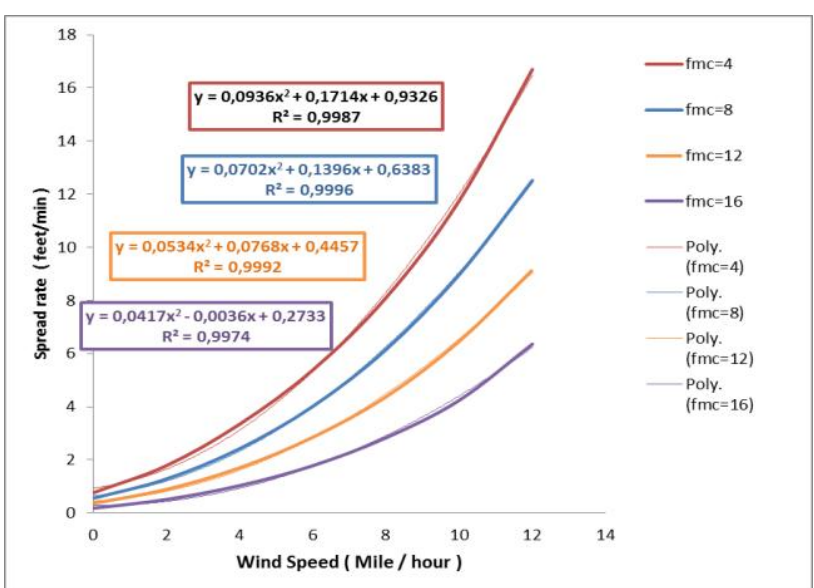

Fig. 1. Plots of FSR in function of wind speed $V$ with varying FMC and the corresponding regression polynomial equations.

The experimental data used in this paper refer to the experimental results performed by Fons 1939 which listed and used by Anderson in his contribution [15].

Fons reported on a series of 198 test fires conducted in a low velocity wind tunnel. Table I states for pine litter the spread rate of surface fires with varying wind velocity and moisture content (Table I). Wind velocity that was measured $1 \mathrm{ft}(0.3 \mathrm{~m})$ above the fuel surface was varied from 2 to 12 $\mathrm{mi} / \mathrm{h}(3.2$ to $19.3 \mathrm{~km} / \mathrm{h})$. This measurement is comparable to mid flame height. Fires were started from a point source and allowed to grow until they were approximately 18 inches $(45.7 \mathrm{~cm})$ in width.
The data of Table I are displayed in Fig. 1 and regression to the obtained curve for each FMC is traced and a 2nd degree polynomial equation is formulated for each curve. The 2 nd degree polynomial equation is found to get the strongest positive correlation $R_{2}$.

The three coefficients $a, b$ \& c of each obtained equation are then plotted in function of FMC to derive the generalized equation as in Table II and Fig. 2.

After plotting the coefficients, regression is made to the plots and the result is shown in Fig. 2.

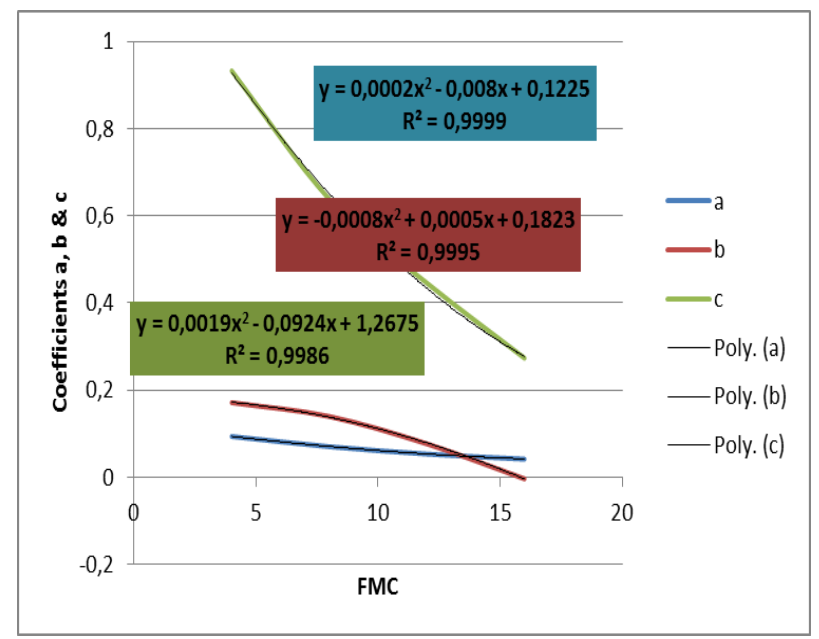

Fig. 2. Plots of the three coefficients in function of FMC and the corresponding regression equations.

Now the equation of FSR could be derived as follows:

$$
\begin{gathered}
\mathrm{FSR} 1=\left(0.0002 \mathrm{FMC}^{2}-0.0008 \mathrm{FMC}^{2}+0.1225\right) \mathrm{V}^{2} \\
+\left(-0.0008 \mathrm{FMC}^{2}+0.0005 \mathrm{FMC}+0.1823\right) \mathrm{V} \\
+\left(-0.0019 \mathrm{FMC}^{2}-0.0924 \mathrm{FMC}+1.2675\right)
\end{gathered}
$$

FSR, as obtained, is an equation that predicts the speed rate in the strict forward direction, the direction of the wind. Equation 1 ignored two important factors: the slope and the angle effect in the different directions.

\section{A. Angle Effect}

TABLE III: ANGLE RATIOS OBTAINED WHEN VARYING WIND SPEED AND A [15]

\begin{tabular}{c|cccc}
\hline \multirow{2}{*}{ Wind Speed (mi/h) } & \multicolumn{5}{|c}{ Angle formed with the direction of wind } \\
\cline { 2 - 5 } 2,2 & 45 & 90 & 135 & 180 \\
4,3 & 0,618 & 0,431 & 0,344 & 0,328 \\
6,4 & 0,48225 & 0,312 & 0,229 & 0,218 \\
8,4 & 0,35175 & 0,205 & 0,145 & 0,142 \\
10,5 & 0,289 & 0,163 & 0,108 & 0,105 \\
12,5 & 0,2245 & 0,115 & 0,07 & 0,066 \\
& 0,208 & 0,103 & 0,056 & 0,057 \\
\hline
\end{tabular}

The angle effect could be deducted using the experimental records also reported in the work of Anderson referring to the readings of Fons (Table III). Ratio of angular distance to the distance of maximum spread or Angle Ratio $\beta \alpha$ is shown in Table III based on varying wind speed and the angle formed with the wind direction $\alpha$.

The angle ratios are plotted and the most appropriate regression equations are conducted (Fig. 3). 


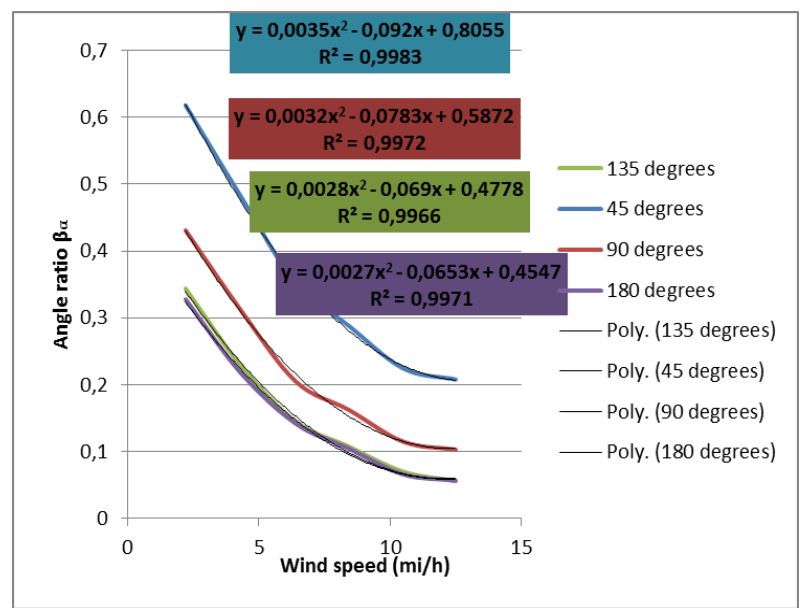

Fig. 3. Plots of Angle ratio in function of wind speed $\mathrm{V}$ with varying the angle $\alpha$ and the corresponding regression polynomial equations.

To generate a generalized equation of the angle ratio, similarly a', b' \& c', the coefficients of the deducted equations of Fig. 3 stated in Table IV, are plotted in Fig. 4.

TABLE IV: THE COEFFICIENTS OF THE POLYNOMIAL EQUATIONS IN

\begin{tabular}{c|ccc}
\multicolumn{4}{|c}{ FUnCTION OF A } \\
\hline$\alpha$ & $a^{\prime}$ & $b^{\prime}$ & $c^{\prime}$ \\
\hline 45 & 0,0035 & $-0,092$ & 0,8055 \\
90 & 0,0032 & $-0,0783$ & 0,5872 \\
135 & 0,0028 & $-0,069$ & 0,4778 \\
180 & 0,0027 & $-0,0653$ & 0,4547 \\
\hline
\end{tabular}

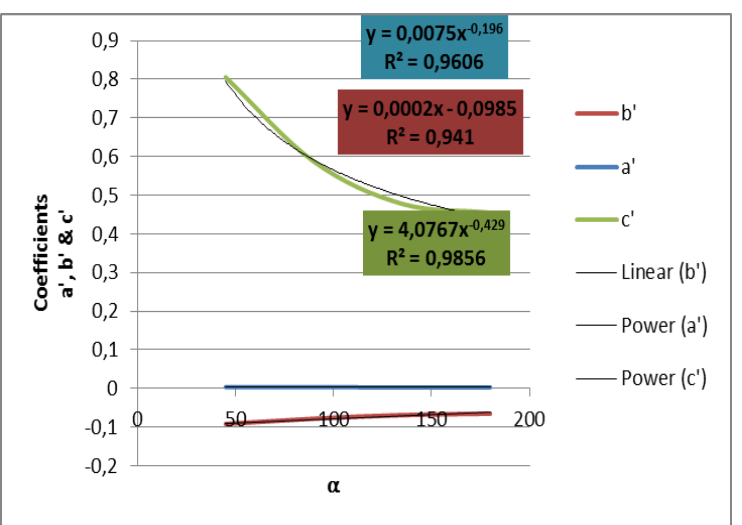

Fig. 4. Plots of the three coefficients in function of $\alpha$ and the corresponding regression equations.

Thus the equation of the Angle Ratio is presented:

$$
\beta_{a}=1 \quad \text { if } \alpha=0^{\circ}
$$

Else,

$$
\begin{array}{r}
\beta_{a}=\left(0.0075 \alpha^{-0.196}\right) V^{2}+(0,0002 \alpha-0,0985) V+ \\
4.0767 \alpha^{-0.429}
\end{array}
$$

\section{B. Slope Effect}

Rothermel [10] entered the effect of slope in his equation as follows:

where

$$
\beta_{s}=5.275 \beta^{-0.3}(\tan (\varphi))^{2}
$$

$\beta=$ packing ratio

$\tan (\varphi)=$ slope of the fuel bed (vertical rise / horizontal distance)

Knowing that packing ratio is the compactness of the fuel bed and it is determined by the fuel model. It is the ratio of fuel bed bulk density (fuel load / fuel bed depth) to fuel particle bulk density. The slope factor is smaller for more tightly compacted fuel.

Now we can derive the final equation of FSR after taking into consideration both effects, slope and the angle with the direction of wind, and merging with the equation of FSR1 (1).

$$
\mathrm{FSR}=\left[\begin{array}{c}
\left(0.0002 \mathrm{FMC}^{2}-0.008 \mathrm{FMC}+0.1225\right) V^{2}+ \\
\left(-0.0008 \mathrm{FMC}^{2}+0.0005 \mathrm{FMC}+0.1823\right) V \\
+\left(0.0019 \mathrm{FMC}^{2}-0.0924 \mathrm{FMC}+1.2675\right) \\
\beta_{a} \times\left((\beta)_{s}+1\right)
\end{array}\right] \times
$$

\section{CONCLUSION AND FUTURE WORK}

JRC Technical Report 2011 stated: "Recent reports indicate increases in fire frequency and severity. The forest fire situation in Lebanon is significantly determined by predominating climatic conditions with prolonged summers (extending from June to October and sometimes even longer), virtually no rain and average daytime temperatures well in excess of $30^{\circ} \mathrm{C}$, reducing the moisture content of forest litter to below $5 \%$. Under these conditions, a small addition of heat (a spark, a match, a cigarette butt) can still be enough to start a violent fire. The steep slopes and the summer and eastern dry autumn winds characterized by high speed and strong desiccating power aggravate the situation [16]". It added: "the Ministry of Agriculture reported that a total of 1200 ha of natural forests are burned every year" [16]. Here appears the urgent need for every effort that could stop the occurrence of fires or at least limit their catastrophic consequences not only on forestry but even on human. This paper presents a new simplified semi-empirical model equation that could predict the behavior of fire by using a limited number of parameters easy to extract.

The proposed equation still needs to be validated by application on past fires in Lebanon and/or other developing countries. Tests are to be implemented on witnessed fire incidences recorded and reported by environmental organizations that aim to achieve sustainable conservation of natural resources.

\section{REFERENCES}

[1] G. L. W. Perry, "Current approaches to modelling the spread of wildland fire: a review," Progress in Physical Geography, vol. 22, no. 2, pp. 222-245, 1998.

[2] W. L. Fons, "Analysis of fire spread in light forest fuels," Journal of Agricultural Research, vol. 72, pp. 93-121,1946,

[3] F. A. Albini, "Estimating wildfire behaviour and effects," General Technical Report INT-30, USDA Forest Service, Intermountain Forest and Range Experiment Station, pp. 1-96, 1976.

[4] A. M. Grishin, "Steady-state propagation of the front of a high-level forest fire," Soviet Physics Doklady, vol. 29, pp. 917-919, 1984.

[5] R. O. Weber, "Analytical models for fire spread due to radiation," Combustion and Flame, vol. 78, pp. 398-408, 1989.

[6] B. W. Butler, M. A. Finney, P. L. Andrews, and F. A. Albini, "A radiation-driven model of crown fire spread," Canadian Journal of Forest Research, vol. 34, pp. 1588-1599, 2004.

[7] M. E. Alexander and M. G. Cruz, "Evaluating a model for predicting active crown fire rate of spread using wildfire observations," Canadian Journal of Forest Research, vol. 36, pp. 3015-3028, 2006. 
[8] A. G. McArthur, "Weather and grassland fire fehaviour," Tech. Rep., Commonwealth Australia, Department of National Development, Forest and Timber Bureau, no. 100, 1966,

[9] B. J. Stocks, M. E. Alexander, and R .A. Lanoville, "Overview of the International Crown Fire Modelling Experiment (ICFME)," Can. J. For. Res., vol. 34, pp. 1543-1547, 2004.

[10] R. C. Rothermel, A Mathematical Model for Predicting Fire Spread in Wildland Fuels, USDA Forest Service, Intermountain Forest and Range Experiment Station, Research Paper INT-115, 1972.

[11] M. A. Finney, FARSITE: Fire Area Aimulator-Model Development and Evaluation, United States Department of Agriculture Forest Service Rocky Mountain Research Station, Research Paper RMRS-RP-4, March 1998

[12] P. L. Andrews, Behave: Fire Behavior Prediction and Fuel Modeling System - Burn Subsystem, Part 1, General Technical Report INT-194, USDA Forest Service, Intermountain Research Station, 1986.

[13] R. E. Burgan and R. C. Rothermel, Behave: Fire Behavior Prediction and Fuel Modelling System - Fuel Subsystem, General Technical Report INT-167, USDA Forest Service, Intermountain Forest and Range Experiment Station, 1984.

[14] R. SchÖning, A. Bachmann, and B. AllgÖwer, GIS-Based Framework for Wildfire Risk Assessment, Final report for the European research project minerve 2, Department of Geography, Division of Spatial Data Handling, University of Zürich, 1997.

[15] H. E Anderson, Predicting Wind-Driven Wildland Fire Size and Shape, Research Paper INT-69, USDA Forest Service, Intermountain Forest and Range Experiment Station, 1983.

[16] Joint Research Centre of the European Commission, Forest Fires in Europe, Middle East and North Africa, 2011.

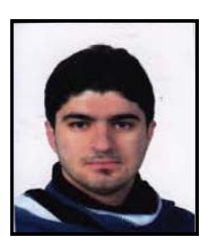

Eng. Ali Karouni has received his degree in electrical and electronics engineering, industrial digital contro major from the Faculty of Engineering, Lebanese University in 2009. He received his master degree in industrial control from the Ecole Doctorale des Sciences et de Technologie- Lebanese University in collaboration with Universite de Technologie de Compiegne-France in 2010. He then was granted a diploma of master in renewable energies from Saint Joseph University-Faculty of Engineering ESIB-Lebanon in collaboration with Ecole Doctorale des Sciences et de Technologie-Lebanese University. He is a now doctoral student at Universite d'Angers-France collaborated with Ecole Doctorale des Sciences et de Technologie-Lebanese University. His research interests include neural networks, pattern recognition, decision theory, optimization, diffusion and cooperative intelligent systems to predict, model and manage a natural disaster: forest fires. He is the first author in 5 refereed international journal and conference papers. He also participated in many international confeneces: WCIT 2010-Istanbul, ICCSLE 2013-Hong Kong, WCIT 2013-Brussels, ICEST 2014-Polland and ICSEM 2014-Paris.

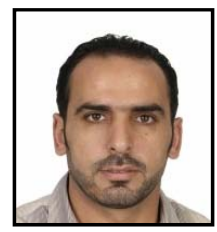

Pr Bassam Daya has received his BE degree in electrical and computer engineering in 1992 from the Lebanese University, Lebanon, the MS degree in automatic control and applied computer in 1993 from the Ecole Centrale of Nantes, France and the $\mathrm{PhD}$ degree in automatic control and applied computer in 1996 from the University of Angers, France. He was an assistant professor from 1994 till 1998 in the University of Angers, France, and worked as research engineer from 1996 till 1998 in UNIVALOIRE Society, Angers, France. From 1998 till 2002 he was an assistant professor at the Lebanese University, IUT of Saida, Lebanon and after it an associated professor from 2002 till 2007 in the same university and he became since 2007 a full professor in the Lebanese University. He was the chief of many projects organized by CEDAR and Ministry of culture in Lebanon in 2006 and in 2009. He has more than 44 published papers. His current research interests are in neural network architecture for robotics systems, object detection and identification.

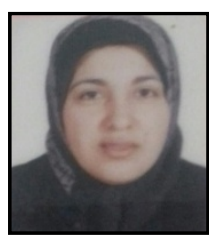

Samia Bahlak has received her degree in electronic engineering in 1991 from the Lebanese University-Faculty of Engineering. Then she received her master degree in industrial and human automatics from LAIH, Valenciennes- France in 1992. In 1997, she received her PH.D. in electronics from IEMN, Valenciennes-France, in the field of modulator acousto-electro-optics. She is currently a senior lecturer at the Lebanese University - IUT of Saida. Her domains of interest are electronics, microelectronics, industrial computer and automata. She has 11 published papers in refereed international journals and conferences.

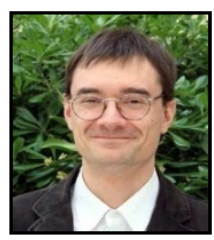

Pr. Pierre Chauvet is currently working as a full professor at the Institute of Applied Mathematics of Université Catholique de l'Ouest (Angers, France) and as a director of the research team of the institute. He is also a member of the Laboratoire d'Ingénierie des Systèmes Automatisés (LISA) research laboratory at Université d'Angers. He holds a Ph.D. (1993) in automatics from Université d'Angers (France) and an HdR ("accreditation to supervise research" - 2001) in computer science from Université Paris 8 (France). His current research interests include artificial neural networks, modelling and simulation of complex systems. biomedical applications, and he has many publications in these fields. He is co-founder or scientific advisor of several companies ("in-silico" experimentation for pharmaceutical corporations, and geostatistics, risk-analysis and simulation in global security), and also co-founder and director of the GRECO (research group on complex systems). 